\title{
CONSUMPTION AND PURCHASING POWER OF THE POPULATION OF BASIC FOOD PRODUCTS
}

\author{
N. Petrova* \\ Department of Management, Trakia University, Stara Zagora, Bulgaria
}

\begin{abstract}
The consumption and purchasing power of the population are key factors in the development of domestic production and sales and an important indicator of the standard of living of the population. The aim of the article is to investigate the development of the consumption and purchasing power of the population of basic food products. The methods used are systematic and comparative analysis; Method of statistical groupings, expert assessments, inductive and deductive methods for generalizing summaries.
\end{abstract}

Key words: consumption, incomes, GDP

\section{INTRODUCTION}

The consumption and the purchasing power of the population are key factors for the development of production and sales at the domestic market and an important indicator for the standard of living of the population. Consumption is the value expression of consumer goods purchased by households. Consumer spending forms more than half of the total costs of a country and is therefore the main component of gross domestic product (GDP).

Factors on which the structure and extent of consumption depend are income, interest rate, direct taxes, consumer preferences, etc.

\section{MATERIAL AND METHODS}

The methods used are systematic and comparative analysis; Method of statistical groupings, expert assessments, inductive and deductive methods for generalizing summaries.

\section{RESULTS AND DISCUSSION}

Satisfying basic human needs is related to the consumption of basic food products. The type and quantity of food consumed depend on the individual tastes and people's preferences, on their culture of nutrition and level of income.

\footnotetext{
*Correspondence to: Nadezhda Petrova, Department of management, Trakia University, Stara Zagora, Bulgaria, tel: 042699 410; fax: 042 699 416,e-mail: nfp@abv.bg
}

During the research period, consumption of one part of the products has increased whereas with others it has significantly decreased (Table 1). Consumption of bread and pasta at an average for one person per household is reduced by $1.8 \mathrm{~kg}$ in 2018 compared to 2017 , and with $22.7 \mathrm{~kg}$ in comparison to the beginning of the period -2010 . There reduces the consumption of basic products of the canning industry - compotes, jams, vegetable preserves and vegetable nectars and juices. In 2010 the consumption of compotes is $15.4 \mathrm{~kg}$ per person, and in 2018 it decreases to $7.3 \mathrm{~kg}$. At the end of the investigated period, consumption of vegetable preserves and vegetable nectars and juices decreases by 3.1 $\mathrm{kg}$ and $0.6 \mathrm{~kg}$, respectively, compared to the beginning of the period.

For a great part of the main food products, the consumption for the research period has increased - meat with $2.3 \mathrm{~kg}$, yogurt with 0.4 $\mathrm{kg}$, yellow cheese with $0.6 \mathrm{~kg}$, fresh and frozen fruits with $6 \mathrm{~kg}$, fresh and frozen vegetables with $1.6 \mathrm{~kg}$. Consumption of soft drinks has increased significantly $-15.6 \mathrm{l}$, also that of alcoholic beverages -7.81 and that of cigarettes -83 pcs.

The changes in the growth and structure of household consumption over the considered period are to a great extent the result of increasing the incomes of the population. As 
PETROVA N.

the National Statistical Institute (NSI) states, in 2018 the annual total income per person is 6 013 BGN. and it increases by $7.6 \%$ compared to 2017 year. For the past ten years the total income per person from household increases
1.6 times. Real household incomes have grown by $7.3 \%$ in 2018 compared to 2017 , with the highest real income index in 2018 versus 2011 $-138.1 \%$.

Table 1. Consumption of main food products average from persons in household

\begin{tabular}{|l|r|r|r|r|r|r|r|r|r|}
\hline Food and drink & $\mathbf{2 0 1 0}$ & $\mathbf{2 0 1 1}$ & $\mathbf{2 0 1 2}$ & $\mathbf{2 0 1 3}$ & $\mathbf{2 0 1 4}$ & $\mathbf{2 0 1 5}$ & $\mathbf{2 0 1 6}$ & $\mathbf{2 0 1 7}$ & $\mathbf{2 0 1 8}$ \\
\hline Bread and pasta - kg & 108,0 & 106,7 & 101,1 & 97,8 & 93,2 & 89,5 & 88,0 & 87,1 & 85,3 \\
\hline Meat-kg & 32,0 & 32,1 & 32,0 & 32,2 & 32,5 & 32,6 & 32,5 & 32,8 & 34,3 \\
\hline Meat products - kg & 13,8 & 14,0 & 14,3 & 14,4 & 14,0 & 13,7 & 13,1 & 13,4 & 13,6 \\
\hline Fish and fishery products - kg & 5,3 & 5,4 & 5,4 & 6,7 & 5,7 & 5,2 & 5,0 & 4,9 & 5,2 \\
\hline Fruit (fresh and frozen) - kg & 43,5 & 47,2 & 46,0 & 50,3 & 50,5 & 47,6 & 49,0 & 50,7 & 49,5 \\
\hline Compotes - kg & 15,4 & 12,4 & 11,6 & 10,7 & 10,1 & 8,7 & 8,3 & 7,7 & 7,3 \\
\hline Jam, marmalades - kg & 0,8 & 0,8 & 0,8 & 0,9 & 0,9 & 0,8 & 0,7 & 0,7 & 0,7 \\
\hline $\begin{array}{l}\text { Vegetables (fresh and frozen) } \\
\text { - kg }\end{array}$ & & & & & & & & & \\
\hline Vegetable preserves - kg & 69,1 & 71,0 & 70,4 & 73,1 & 70,9 & 68,4 & 70,0 & 68,0 & 70,7 \\
\hline Soft drinks-1 & 12,9 & 13,8 & 13,5 & 12,9 & 12,4 & 11,2 & 10,6 & 10,5 & 9,8 \\
\hline Alcoholic beverages-1 & 50,9 & 49,5 & 56,9 & 60,8 & 61,1 & 59,5 & 58,8 & 65,3 & 66,5 \\
\hline Cigarettes - 83 pcs & 23,6 & 23,2 & 26,3 & 27,1 & 28,4 & 29,2 & 27,3 & 28,9 & 31,0 \\
\hline Si & 591 & 547 & 601 & 596 & 603 & 647 & 639 & 656 & 674 \\
\hline
\end{tabular}

Source: National Statistical Institute

Improvements with regard to the income structure (Table 2) are also observed. Wage incomes form $55 \%$ of total household incomes - a circumstance determined both by the continuing in 2018 wage rise and by the sustaining high employment and decreasing unemployment. As a result of the healthy labour market situation and the economy as a whole, social benefits and aid already form below $2.5 \%$ of household income, despite the increase in certain social payments.

Table 2. Total income and other funds per person from household by source

\begin{tabular}{|l|r|r|r|r|r|}
\hline Sources of income in BGN & \multicolumn{1}{|c|}{2010} & \multicolumn{1}{|c|}{2012} & 2014 & \multicolumn{1}{|c|}{2016} & \multicolumn{1}{c|}{2018} \\
\hline Total income & $\mathbf{3 6 4 8}$ & $\mathbf{4 3 2 7}$ & $\mathbf{4 8 1 3}$ & $\mathbf{5 1 6 7}$ & $\mathbf{6 0 1 3}$ \\
\hline Gross total income & 3474 & 4121 & 4643 & 4989 & 5747 \\
\hline Wages and salaries & 1857 & 2281 & 2610 & 2807 & 3336 \\
\hline Other than wages and salaries & 78 & 109 & 166 & 150 & 70 \\
\hline From self-employment & 228 & 330 & 360 & 319 & 420 \\
\hline From property & 28 & 41 & 39 & 36 & 30 \\
\hline From pensions & 1128 & 1153 & 1242 & 1432 & 1645 \\
\hline Unemployment compensations & 23 & 29 & 26 & 20 & 20 \\
\hline Family allowances for children & 33 & 35 & 42 & 40 & 79 \\
\hline Other benefits and allowances & 67 & 82 & 109 & 119 & 57 \\
\hline Regular transfers from other households & 33 & 61 & 50 & 65 & 89 \\
\hline Sales takings & 35 & 35 & 32 & 31 & 23 \\
\hline Other incomes & 139 & 171 & 137 & 147 & 244 \\
\hline Withdrawn savings & 125 & 154 & 144 & 179 & 241 \\
\hline Loans and credits & 38 & 60 & 61 & 57 & 109 \\
\hline
\end{tabular}

Source: National Statistical Institute

In 2018, Bulgarian households have spent 5 $772 \mathrm{BGN}$. at the average per person which is $10.6 \%$ more than in 2017. For the analysed period household expenditure increases 1.7 times.
Data on the cost structure of household expenditure is highly positive. In 2018, the relative share of food costs from the total amount of expenditure is $29.7 \%$, which is 0.4 percentage points less than in 2017 and 7.5 percentage points less in comparison with 2010. 
In 2018, households ' purchasing power increases compared to 2017 for almost all basic food products except white bread, cucumbers, peppers, apples, grapes, butter. Purchasing power has increased most for potatoes, rice, dried beans, fresh milk, pork and poultry meat, sugar.

\section{CONCLUSIONS}

In conclusion, there can be summarized several factors, which will continue to have an impact on consumption:

Consumption will depend both directly and indirectly on the development of the labour market. Employment and average wage growth continue to rise, albeit at relatively slow rates.

The dynamics of consumption will be formed by the consumer attitudes of the population. The intentions of the Bulgarian citizens strengthen towards spending a large sum of money for improvements of their homes or for buying a car. The increase in the propensity for large costs and purchases of durable goods means that growth in consumption is likely to accelerate in the coming years.

Household deposits are significantly increasing and low interest rates are expected to boost consumer spending.
The increase in consumption will be determined by better access to credit in the coming years. The interest rates on loans have decreased over the past year, which facilitates the servicing of the already assumed obligations and the boost of new consumer credits.

\section{REFERENCES}

1. Aleksiev G., N. Kostadinova, Local consumption and processing of Bulgarian organic products, Scientific papers, Volume LXI, Vol. 2, Academic Publishing House of the Agricultural University - Plovdiv, ISSN 1312-6318, pp. 17-27, 2018

2. Kostov D., Quality Management, Iskra MM, Stara Zagora, 2007

3. Nencheva I., T. Atanasova., Market orientation of Bulgarian agricultural production - realities and European challenges, Agrobusiness and Rural Economy, Innovation, Growth Reports, YIVarna, 2017

4. Stoycheva, I., Regional structural economic disparities in Bulgaria, Trakia Journal of Sciences, №4, pp381-385, 2017

5. https://www.nsi.bg/en/content/5640/househ olds-income-expenditure-and-consumption 